\title{
Longitudinal predictors of early language in infants with Down syndrome: a preliminary study
}

Article

Accepted Version

Creative Commons: Attribution-Noncommercial-No Derivative Works 4.0

Mason-Apps, E., Stojanovik, V., Houston-Price, C. and Buckley, S. (2018) Longitudinal predictors of early language in infants with Down syndrome: a preliminary study. Research in Developmental Disabilities, 81. pp. 37-51. ISSN 0891-4222 doi: https://doi.org/10.1016/j.ridd.2017.12.021 Available at https://centaur.reading.ac.uk/74700/

It is advisable to refer to the publisher's version if you intend to cite from the work. See Guidance on citing.

To link to this article DOI: http://dx.doi.org/10.1016/j.ridd.2017.12.021

Publisher: Elsevier

All outputs in CentAUR are protected by Intellectual Property Rights law, including copyright law. Copyright and IPR is retained by the creators or other copyright holders. Terms and conditions for use of this material are defined in the End User Agreement.

www.reading.ac.uk/centaur 
Central Archive at the University of Reading

Reading's research outputs online 


\begin{abstract}
Purpose: Children with Down syndrome (DS) typically have marked delays in language development relative to their general cognitive development, with particular difficulties in expressive compared to receptive language. Although early social communication skills, including gestures and joint attention, have been shown to be related to later language outcomes in DS, knowledge is limited as to whether these factors exclusively predict outcomes, or whether other factors (e.g. perceptual and non-verbal skills) are involved. This study addressed this question. Method: Longitudinal data for a group of infants with DS $(n=14)$ and a group of typically-developing (TD) infants $(n=35)$ were collected on measures that have been shown to predict language in TD infants and/or those with developmental delays. These included: non-verbal mental ability, speech segmentation skills, and early social communication skills (initiating and responding to joint attention, initiating behavioural requests). Results: Linear regression analyses showed that speech segmentation and initiating joint attention were the strongest predictors of later language in the TD group, whereas non-verbal mental ability and responding to joint attention were the strongest predictors of later language for infants with DS. Conclusions: Speech segmentation ability may not determine language outcomes in DS, and language acquisition may be more constrained by social communication and general cognitive skills.
\end{abstract}

\title{
1.0. Introduction
}

Typically-developing (TD) childrens' language acquisition is supported by general cognitive, social and perceptual skills. However knowledge is limited regarding which factors (including cognitive, perceptual and social abilities) in the first 2 years of life are important 
for language outcomes in children with genetic disorders. One population known to be at risk for language difficulties are individuals with Down syndrome (DS).

DS or trisomy 21 is the most common genetic cause of intellectual disability (Martin, Klusek, Estigarribia, \& Roberts, 2009) with prevalence estimates of 1 in 691 live births (Parker et al., 2010). DS results from a partial or complete duplication of chromosome 21 (Epstein, 1986). Children with DS have significant expressive vocabulary deficits compared to TD children matched for nonverbal mental age (NVMA) (Næss et al., 2011). Receptive and expressive syntactic skills are areas of weakness (Chapman, Schwartz, \& Kay-Raining Bird, 1991; Martin et al., 2009). Lexical skills tend to be relatively stronger than grammatical skills (Caselli, Monaco, Trasciani \& Vicari, 2008), and receptive vocabulary in particular is often reported as a relative strength (Galeote, Sebastian, Checa, Rey \& Soto, 2011). Gesture production at 24 and 36 months of age has been shown to predict later vocabulary development (Zampini \& D'Odorico, 2011). However, other than gesture, little is known about early predictors (prior to 24 months of age) of language outcomes. Identifying prelinguistic predictors of language is important both for enabling early identification of individuals particularly at risk of language deficits, and for enhancing our theoretical understanding of language development by revealing the factors that underpin language acquisition (Watt, Wetherby, \& Shumway, 2006).

We first review the early social communication, speech segmentation and general cognitive skills that have been shown to predict language outcomes in TD children.

\subsection{Early social communication skills}

Early social communication skills, such as initiating and responding to joint attention and initiating behavioural requests have long been known to be related to later language outcomes in TD children. Responding to joint attention (RJA) refers to "the child's ability to 
change the direction of head and eyes in response to a change in direction of adult focus" (McDuffie, Yoder, \& Stone, 2005: 1081). It emerges between 6 and 12 months of age in TD infants and continues to develop until around 18 months of age (Butterworth \& Jarrett, 1991; Delgado et al., 2002; Morales et al., 2000). An important progression occurs between 12 and 18 months, when infants develop the ability to follow another person's attention to a target outside of their visual field (Butterworth \& Jarrett, 1991; Delgado et al., 2002). Also in this period, the child develops the ability to engage in coordinated joint attention, when the child can alternate their gaze back and forth between a person and an object during social interaction (Adamson, Bakeman, Deckner \& Romski, 2009; Kasari, Freeman, Mundy \& Sigman, 1995). The ability to respond to joint attention facilitates language development by allowing children to avoid mapping errors during word learning. Despite some variety in the methods used to assess RJA, differences in RJA in TD infants have been reported to be related to expressive and receptive vocabulary and other language measures, both concurrently and longitudinally (e.g., Carpenter, Nagell, Tomasello, Butterworth, \& Moore, 1998; Delgado et al., 2002; Morales et al., 2000; Mundy \& Gomes, 1998; Mundy, Kasari, Sigman, \& Ruskin, 1995). Individual differences in the ability to respond to joint attention predict language ability even after controlling for initial language status (Morales et al., 2000) and initial mental and chronological age (Mundy \& Gomes, 1998; Mundy et al., 1995). RJA is reported to be a unique predictor of language comprehension over and above the skills of initiating joint attention and behavioural requests (Mundy \& Gomes, 1998).

Fewer studies have explored RJA in infants with DS, although some studies include infants with DS within a mixed aetiology group. Of the studies that have measured early social communication skills in this population, Mundy et al. (1995) found that infants with DS (between 12 and 36 months, mean age 22.5 months) showed deficits in RJA compared to 
mental age-matched (MA) controls, but RJA was not a significant predictor of expressive or receptive language. RJA was also found not to be a significant predictor of later vocabulary skills in Italian speaking infants with DS aged 24 months (Zampini, Salvi \& D'Odorico, 2015). In contrast, Sigman and Ruskin (1999) reported that children with DS (between 2 and 4 years, mean age 31.4 months) were significantly better at RJA than a MA-matched group of children with autism and their performance did not differ significantly from that of a TD group, or a group of developmentally-delayed children (also matched for MA). Although RJA was related to concurrent language ability in infants with DS, it did not predict gains in expressive language a year later.

Initiating joint attention (IJA) and initiating behavioural requests (IBRs) are the two pragmatic functions that infants most frequently use to engage in intentional communication before they can use words (Wetherby, Cain, Yonclas, \& Walker, 1988). The emergence of these skills represents the development of social-cognitive processes that may provide a foundation for subsequent language development, such as the capacity for representational thought and understanding that experiences can be shared (Mundy et al., 1995). Engaging in these communicative behaviours often elicits contingent verbal responses from caregivers, thereby increasing the linguistic input to the child (Yoder \& Munson, 1995; Yoder \& Warren, 1993, 1998). It is therefore not surprising that IJA is both concurrently and longitudinally related to receptive and expressive vocabulary in TD infants (Bates, Thal, Whitesell, Fenson, \& Oakes, 1989; Blake, 2000; Desrochers, Morissette, \& Ricard, 1995; Mundy, et al., 1988; Sigman \& Ruskin, 1999; Ulveand \& Smith, 1996; Watt et al., 2006) and children with DS syndrome (Harris, Kasari \& Sigman, 1996; Mundy et al., 1995; Zampini et al., 2015). Similarly, IBRs are concurrently and longitudinally related to receptive and expressive language skills in TD children (Camaioni, Castelli, Longobardi, \& Volterra, 1991; Mundy et 
al., 1988; Mundy et al., 1995; Smith \& von Tetzchner, 1986; Ulveand \& Smith, 1996) and concurrently related to language in infants with DS (Sigman \& Ruskin, 1999).

Although these studies highlight clear links between IJA and IBR and language, the unique predictive value of these skills longitudinally is unclear, as not all studies control for differences in initial language status, cognitive ability, or other non-verbal communication skills (a criticism raised by Mundy \& Gomes, 1998, and Yoder \& Warren, 2004). Studies that have controlled for these factors report conflicting findings regarding the unique predictive value of IBR and IJA. In TD children, some studies have found IJA to account for unique variance in expressive language scores, when controlling for initial chronological age (CA), MA, and expressive language (Mundy \& Gomes, 1998), or for all pre-linguistic skills correlated with expressive language outcome measures (Watt et al., 2006). However, Mundy et al. (1995) found no relationships between IBR or IJA and receptive or expressive language in a TD group when initial language, MA, motor age, and other non-verbal communication abilities (such as joint attention) were controlled for. In the same study, IBR predicted the expressive (but not receptive) language of infants with DS, and IJA was not related to language outcomes when other factors were controlled for (Mundy et al., 1995).

In summary, while responding to joint attention is clearly related to language outcomes in TD children, it is unclear whether this factor predicts language in children with DS and whether initiating joint attention and behavioural requests are related to language outcomes in either group.

\subsection{Speech segmentation}

The ability to segment and recognise words embedded in fluent speech is vital for language comprehension. Since most of the speech directed towards infants is in the form of continuous multiword utterances, infants must be able to extract and identify individual 
words in order to map meaning onto words (Newman et al., 2006). In a retrospective analysis, Newman et al. (2006) found that children with larger expressive vocabularies at age 2 and better language scores at age 4 performed better on speech segmentation measures taken between 7.5 and 12 months. This relationship was not mediated by general cognitive function, implying that the relationship is specific to language. A recent study by Singh, Reznick and Xuehua (2012) also found speech segmentation abilities at 7.5 months to be strongly associated with productive vocabulary at 24 months. No study has investigated whether speech segmentation ability predicts later language outcomes in children with DS.

\subsection{General cognitive ability}

General cognitive ability is a good indicator of concurrent language status in TD infants (Bishop \& Mogford, 1993) and is reported to be the strongest predictor of language development in hearing-impaired children under 5 years (Sarant, Hughes \& Blamey, 2010). However, these findings do clarify whether or how language and cognitive development are inter-related, and theoretical approaches on this differ. From innate modularity perspective, language acquisition is constrained by specialised mechanisms, and largely independent of other cognitive abilities (Fodor, 1983). From a neuro-constructivist perspective, on the other hand, language emerges from interactions between genes and the environment (KarmiloffSmith, 1998; Deak, 2014). The theoretical debate primarily concerns whether language is a domain-general or domain-specific ability and the extent to which successful language acquisition depends on general cognitive ability. In typical development, language acquisition occurs alongside developments in sensory, motor and cognitive domains. In developmentallydisordered populations, however, the relationship between language and general cognitive abilities can be uneven and has been the subject of much debate (Deak, 2014; Pinker, 1999; Stojanovik, 2014). 


\subsection{Current study}

As discussed in the literature review above, language outcomes in TD children are underpinned by early social communication skills, speech segmentation skills and general non-verbal cognitive skills. Less is known about how these early skills are related to language outcomes in children with developmental disorders, such as DS. Previous research has typically considered only one potential predictor at a time, and we know little about the predictive role of speech segmentation skills and non-verbal mental ability in this population. Studying the development of atypical populations, in which we see uneven patterns of development of language and other non-verbal skills, not only allows us to establish the linguistic precursors of language in the relevant population, but also enables us to address questions within theoretical debates on language acquisition, such as whether certain predictor skills are necessary or sufficient for language acquisition, and whether the timing of their emergence impacts on developmental outcomes. Thus, longitudinal studies of language acquisition and general cognitive development in children with DS tell us something about typical language acquisition, which we could not learn from studying TD infants alone.

This study is the first prospective longitudinal study to investigate the development of early language skills in infants with DS and TD infants in terms of the predictive contribution of non-verbal cognitive ability, speech segmentation and early social communication skills (including RJA, IBR, IJA). The aims of the study are to establish the unique predictive value of each skill when all other predictors and initial language status are controlled, and to ascertain whether the same factors are predictive of outcomes in the TD and DS populations.

\subsection{Method}


This was a longitudinal study, with measures collected at 3 time points approximately 6 months apart. Predictor measures were collected at time points 1 and 2 and language measures were collected at all 3 time points.

\subsection{Participants}

There were two groups of participants: 14 infants with DS (4 girls) recruited through charities supporting individuals with DS (all with trisomy 21) and 35 TD infants (18 girls). All TD infants were being raised in monolingual English-speaking environments; three infants with DS were being raised bilingually or multilingually (1 Bulgarian/Italian, 1 Spanish and 1 Serbian/Croatian/Greek), but English was the primary and dominant language for all infants. Fischer's exact tests showed that there were no significant differences between the two groups at Time Point 1 (TP1) on demographic measures: gender ( $p=.250)$; history of ear infections $(p=.473)$; maternal education $(p=.541)$; maternal employment status $(p=$ $.270)$; co-habiting spouse $(p=.271)$; paternal education $(p=.294)$; paternal employment (100\% for both groups). The only significant difference was for 'other languages' $(p=.020)$. The number of participants who returned for testing, along with the mean ages at each time point are presented in Table 1 .

Table 1: Mean age and number of participants at each time point

\begin{tabular}{|c|c|c|c|c|c|c|}
\hline & TD-TP1 & TD-TP2 & TD-TP3 & DS-TP1 & DS-TP2 & DS-TP3 \\
\hline & 35 & 33 & 32 & 14 & 13 & 13 \\
\hline $\begin{array}{l}\text { Mean Age } \\
\text { (Range in } \\
\text { days) }\end{array}$ & $\begin{array}{c}10 \text { months } \\
10 \text { days } \\
(281-335 \\
\text { days })\end{array}$ & $\begin{array}{c}16 \text { months } \\
23 \text { days } \\
\text { (489-536 } \\
\text { days) }\end{array}$ & $\begin{array}{c}23 \text { months } \\
1 \text { day } \\
(678-725 \\
\text { days })\end{array}$ & $\begin{array}{c}19 \text { months } \\
17 \text { days } \\
\text { (551-666 } \\
\text { days) }\end{array}$ & $\begin{array}{c}26 \text { months } \\
4 \text { days } \\
\text { (741-899 } \\
\text { days) }\end{array}$ & $\begin{array}{c}32 \text { months } \\
17 \text { days } \\
\text { (931-1069 } \\
\text { days) }\end{array}$ \\
\hline
\end{tabular}

Note: TD-TP1, typically developing, Time Point 1; TD-TP2, typically developing, Time Point 2; TDTP3, typically developing, Time Point 3; DS-TP1, Down syndrome, Time Point 1; DS-TP2, Down syndrome, Time Point 2; DS-TP3, Down syndrome, Time Point 3 
The TD infants did not differ from the infants with DS on non-verbal ability $(t$ (14.6) $=-1.454, \mathrm{p}=.167)$ (see Table 2 for descriptive statistics).

\subsection{General Testing Procedure}

At TP1, participants completed the following assessments: 1) Speech Segmentation, including the Strong-Weak and Weak-Strong Tasks adapted from Nazzi, Paterson, and Karmiloff-Smith (2003); 2) Early Social Communication Scales (ESCS), which provides measures of Initiating Behavioural Requests, Initiating and Responding to Joint Attention (Mundy, Hogan, \& Doehring, 1996); 3) Mullen Scales of Early Learning, which provides a measure of Non-Verbal Mental Ability (Mullen, 1995); and 4) Preschool Language Scales-4, which provides measures of Auditory Comprehension and Expressive Communication (Zimmerman, Steiner, \& Pond, 2002). Assessments were carried out in the order listed. In addition, in the week prior to their visit, parents were sent the Reading Communicative Development Inventory (Reading CDI) (Hamilton, Plunkett, \& Schafer, 2000), which provides measures of Receptive and Expressive Vocabulary. At TP2, infants completed all the TP1 assessments except Speech Segmentation. At TP3, infants completed the Preschool Language Scales-4, and parents completed the Reading CDI prior to their visit. At TP1 and TP2, testing was conducted at the University of [REMOVED FOR REVIEW]. At TP3, testing was conducted in participants' homes, unless parents opted to come to the University. These time points were chosen because speech segmentation develops between 7.5 and 12 months of age in TD children, joint attention develops between 6 and 18 months, and first words are acquired around 12 months of age in TD children and around 21 months in children with DS. In order to capture the crucial precursor milestones in the TD cohort, and ensure that the children with DS are of comparable mental age (so they are developing the precursor milestones), and importantly, to assess precursors to language while they are still 
precursors, we recruited TD infants between 9 and 11 months and infants with DS between 18 and 20 months (matched on non-verbal MA) at TP1.

\subsection{Measures}

\subsubsection{Speech Segmentation}

The task was adapted from Nazzi et al., (2003), using software developed by CreaghOsborne and Floccia (2008). The tasks employed a preferential listening paradigm to measure infants' ability to recognise words embedded in fluent speech after familiarisation to these in isolation. Two tasks were conducted: one assesses infants' ability to segment bisyllabic words with a strong-weak stress pattern (Strong-Weak Task), and one assesses the ability to segment bisyllabic words with a weak-strong stress pattern (Weak-Strong Task).

For each task, there were four target nouns: kingdom, hamlet, doctor, and candle for the Strong-Weak Task, and guitar, surprise, balloon, and device for the Weak-Strong Task. A different six-sentence passage was recorded for each target word (see Appendix 1). All recording was conducted in a sound-proof booth. Passages were recorded in a lively Motherese voice by a female native speaker of British English. The average duration of the passages was 14.2 seconds, and the first occurrence of the target word was always within the first second of the corresponding passage. Each target noun was additionally recorded as 15 isolated occurrences, by the same female speaker, for use in the familiarisation phase. These isolated word-lists were all 16.5 seconds long.

The Strong-Weak and Weak-Strong Tasks followed the same procedure. The order of tasks was counterbalanced and participants had a 5 to 10 minute break between them. Infants sat on their mother's lap in an enclosed booth while completing the tasks (see Figure1). The procedure is described in Appendix 2. 


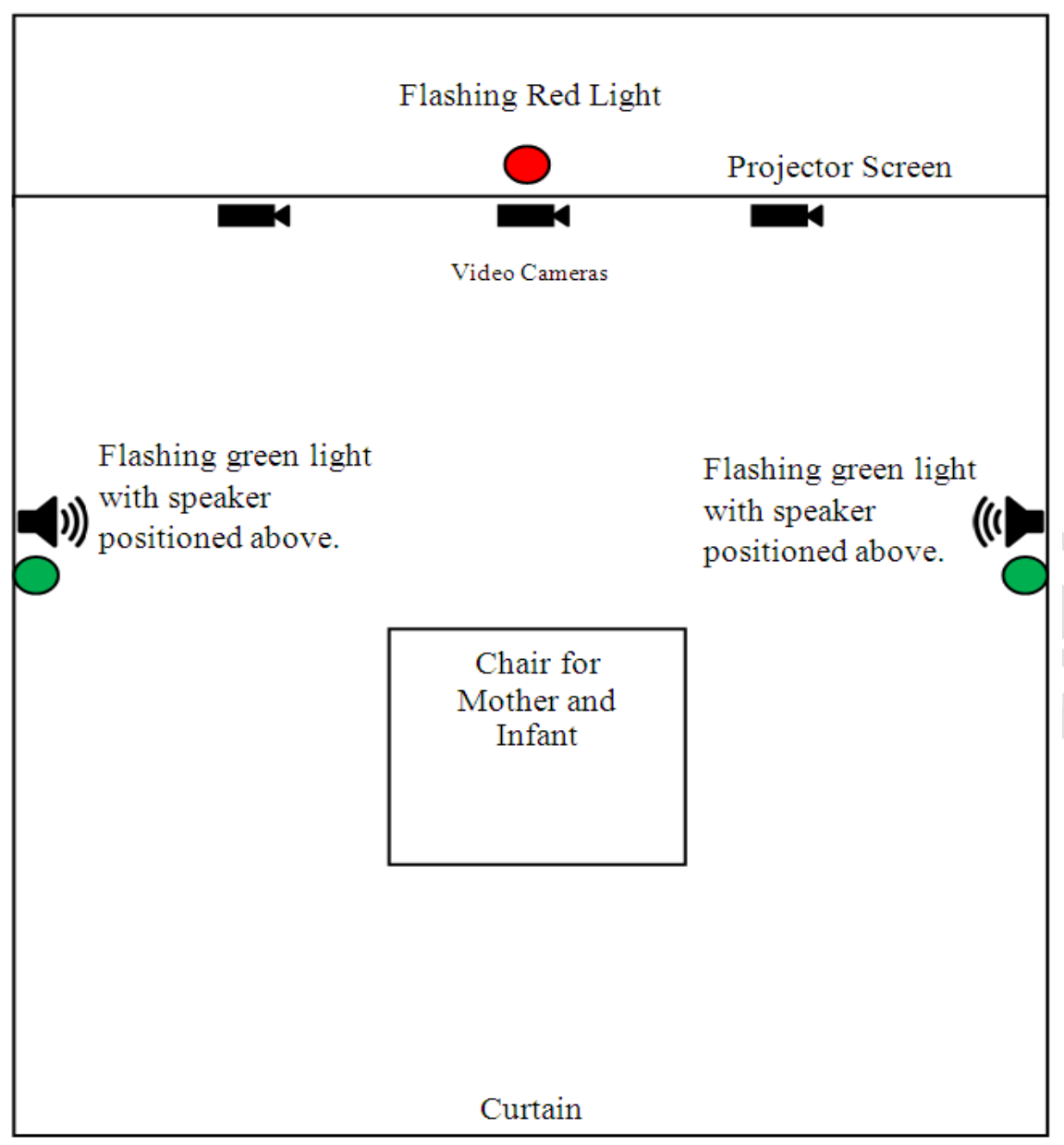

Figure 1: Layout of testing booth used for speech segmentation tasks (not to scale).

A recognition index was calculated for each infant and each task (Strong-Weak and Weak-Strong) by subtracting the mean orientation time to the passages containing the two words not heard in the familiarisation phase from the mean orientation time to the passages containing words heard in the familiarisation phase. A recognition index greater than 0 indicated that infants listened longer to the passages containing the familiarised words (implying they recognised these words from the fluent speech). Parents were asked if their child knew any of the target words. At TP1, none of the parents reported that infants understood or said any of the target words.

\subsubsection{Early Social Communication Scales}


Tasks selected from the abridged version of the Early Social Communication Scales (Mundy, Hogan, \& Doehring, 1996) were used to derive measures of IJA, IBRs and RJA. For descriptions of the tasks, see Mundy et al. (1996). Coding of behaviours followed the coding scheme in the Early Social Communication Scales manual (Mundy et al., 1996).

\subsubsection{Initiating Joint Attention}

Five behaviours were coded: Eye Contact (child makes eye contact with tester while tester manipulates an inactive mechanical toy); Alternates (child alternates looking between active object and tester's eyes); Points (child extends index finger to point at active toy, picture in book, or any other unobtainable object or event); Shows (child raises toy towards tester's face while looking at tester); and Bids to Caregiver (Eye Contact, Alternates, Points, or Shows directed towards caregiver).

\subsubsection{Initiating Behavioural Requests}

Six behaviours were coded: Eye Contact (child makes eye contact with tester when object is inactive, and child is not touching it); Reaches (child extends arm towards out of reach object); Appeals (child makes eye contact while reaching); Points (child uses extended index finger to indicate desire for object/event); Gives (child pushes, throws or hands object to tester to request that she repeats action or removes object); and Bids to Caregiver (Eye Contact, Reaches, Appeals, Points or Gives directed towards the caregiver).

\subsubsection{Responding to Joint Attention}

Two behaviours were coded: Following Proximal Points (in Book Presentation task, child immediately turns head and eyes to follow tester's points to pictures in book); and Following Line of Regard (in Gaze-Following Task, child turns head and directs eyes in correct direction and beyond index finger of tester who points to posters in room). 


\subsubsection{Mullens Scales of Early Learning (MSEL)}

Non-Verbal Mental Ability (NVMA) was assessed using the MSEL (Mullen, 1995), a standardised measure of cognitive functioning for infants aged 0 to 68 months. The Gross Motor, Visual Reception, and Fine Motor scales were administered. NVMA scores were derived by combining the raw scores of the Visual Reception and Fine Motor scales.

\subsubsection{Preschool Language Scales-4 (PLS-4)}

Auditory Comprehension (AC) and Expressive Communication (EC) were assessed using the PLS-4 (Zimmerman et al., 2002), designed for children from birth to 6 years 5 months. PLS-4 provides norm-referenced test scores for both scales (AC and EC) and a Total Language (TL) score. Standardised scores were not used, to enable comparisons between the language abilities of the two groups, who differed in CA, and because standardised scores were often the lowest possible value (55) for infants with DS, obscuring the variability in their ability.

\subsubsection{Reading Child Development Inventory (RCDI)}

Receptive and Expressive Vocabulary scores were measured using the Reading CDI, an adaptation of the Oxford CDI (Hamilton et al., 2000). The instrument comprises a checklist of words that children might know, and additional sections for word endings, word forms, and sentences. Parents were asked to indicate which words their child understood and said.

\subsubsection{Data Analysis}

We first report between-group comparisons on each measure at each time point using independent sample t-tests to identify where the two groups differ in their performance.. Following this, we present the analysis of the speech segmentation task which was administered at TP1. First, we use one-sample t-tests to establish if the recognition indices of each group (TD and DS) on each task (Strong-Weak and Weak-Strong) differ significantly 
from 0. A significant difference indicates that listening times were longer for passages containing words heard during the familiarisation phase, and therefore that infants were able to segment words from fluent speech. To investigate whether the two groups' performance was comparable on this task, we used $2 \times 2$ mixed design analysis of variance model with condition (Strong-Weak vs Weak Strong) as the within-subjects factor, and group (TD vs DS) as the between-subjects factor, Finally, to address longitudinal relationships between variables we present a series of partial correlation and multiple linear regression analyses to identify the relationships between predictor variables and later language outcomes, and the unique predictors of language outcomes in each group. Similar analyses were used in Delgrado et al., (2002), Morales et al., (2000), Mundy \& Gomes (1998), Mundy et al., (1995), Yoder \& Warren (2004), Zampini et al., (2015). Because standardised scores could not be used for the DS group (as detailed in 2.3.5), we used partial correlations to control for any potential effects of chronological age. For the multiple linear regression analysis, we used the Enter method, placing Age and Time 1 language scores in Block 1, and significantly correlated predictor variables in later Blocks. This method allowed us to identify how much variance in later language scores (at TP2 and TP3) could be uniquely explained by any significantly related predictor variables, whilst controlling for Age and initial language status.

\subsection{Results}

\subsection{Between-group comparisons: Language and non-verbal ability}

Table 2 presents the mean scores for the two groups on the language, social communication and non-verbal measures collected at each time point.

Table 2: Mean scores at each time point (raw scores and standard deviations) 


\begin{tabular}{|c|c|c|c|c|c|c|c|c|c|}
\hline & $\begin{array}{l}\text { TD-TP1 } \\
(\mathrm{n}=35)\end{array}$ & $\begin{array}{c}\text { DS-TP1 } \\
(\mathrm{n}=14)\end{array}$ & t-test & $\begin{array}{c}\text { DS-TP2 } \\
(\mathrm{n}=13)\end{array}$ & $\begin{array}{l}\text { TD-TP2 } \\
(\mathrm{n}=32)\end{array}$ & t-test & $\begin{array}{l}\text { TD-TP3 } \\
(\mathrm{n}=31)\end{array}$ & $\begin{array}{c}\text { DS-TP3 } \\
(\mathrm{n}=13)\end{array}$ & t-test \\
\hline $\begin{array}{l}\text { NVMA } \\
\text { (MSEL) }\end{array}$ & $\begin{array}{c}32.4 \\
\text { (sd.2.09) }\end{array}$ & $\begin{array}{c}35.2 \\
(\mathrm{sd} .5 .55)\end{array}$ & $\begin{array}{c}t(14.5)=-1.85 \\
p=.085\end{array}$ & $\begin{array}{c}43.6 \\
\text { (sd.6.0) }\end{array}$ & $\begin{array}{c}45.1 \\
(\mathrm{sd} .3 .19)\end{array}$ & $\begin{array}{c}t(13.76)=0.85 \\
p=.409\end{array}$ & N/A & $\mathrm{N} / \mathrm{A}$ & N/A \\
\hline AC (PLS-4) & $\begin{array}{c}17.5 \\
\text { (sd.1.09) }\end{array}$ & $\begin{array}{c}19.6 \\
(\mathrm{sd} .4 .24)\end{array}$ & $\begin{array}{c}t(13.7)=-1.91 \\
p=.078\end{array}$ & $\begin{array}{c}24.6 \\
(\mathrm{sd} .3 .82)\end{array}$ & $\begin{array}{c}23.4 \\
\text { (sd.2.25) }\end{array}$ & $\begin{array}{c}t(38)=-1.20 \\
p=.239\end{array}$ & $\begin{array}{c}34.5^{*} \\
\text { (sd.5.41) }\end{array}$ & $\begin{array}{c}\text { 30.0* } \\
\text { (sd.4.97) }\end{array}$ & $\begin{array}{c}t(42)=2.55 \\
p=.015\end{array}$ \\
\hline EC (PLS-4) & $\begin{array}{c}19.1 \\
(\mathrm{sd} .2 .06)\end{array}$ & $\begin{array}{c}20.4 \\
\text { (sd.2.98) }\end{array}$ & $\begin{array}{c}t(18.2)=-1.50 \\
p=.152\end{array}$ & $\begin{array}{c}23.8 * * \\
\text { (sd.1.64) }\end{array}$ & $\begin{array}{c}25.8 * * \\
\text { (sd.1.85) }\end{array}$ & $\begin{array}{c}t(38)=3.09 \\
p=.004\end{array}$ & $\begin{array}{l}34.8 * * * \\
\text { (sd.5.24) }\end{array}$ & $\begin{array}{l}\text { 26.5**** } \\
\text { (sd.1.66) }\end{array}$ & $\begin{array}{c}t(40.3)=7.99, \\
p<.001\end{array}$ \\
\hline TLS (PLS-4) & $\begin{array}{c}36.5 \\
(\mathrm{sd} .2 .72)\end{array}$ & $\begin{array}{c}40.0 \\
\text { (sd.6.85) }\end{array}$ & $\begin{array}{c}t(14.7)=-1.85 \\
p=.085\end{array}$ & $\begin{array}{c}48.4 \\
(\mathrm{sd} .4 .93)\end{array}$ & $\begin{array}{c}49.2 \\
(\mathrm{sd} .3 .61)\end{array}$ & $\begin{array}{c}t(38)=0.55 \\
p=.587\end{array}$ & $\begin{array}{r}\text { 69.3**** } \\
(\text { sd.10.2) }\end{array}$ & $\begin{array}{l}\mathbf{5 6 . 5 * * *} \\
(\text { sd.6.09) }\end{array}$ & $\begin{array}{c}t(36.7)=5.14, \\
p<.001\end{array}$ \\
\hline RV (RCDI) & $\begin{array}{c}17.9 * \\
\text { (sd.20.9) }\end{array}$ & $\begin{array}{c}63.3 * \\
(\mathbf{s d} .55 .7) \\
\end{array}$ & $\begin{array}{c}t(13.3)=-2.87 \\
p=.013\end{array}$ & $\begin{array}{c}146 \\
(\mathrm{sd} .95 .1) \\
\end{array}$ & $\begin{array}{c}133 \\
\text { (sd.87.8) } \\
\end{array}$ & $\begin{array}{c}t(40)=-0.41 \\
p=.687\end{array}$ & $\begin{array}{l}\text { 344**** } \\
\text { (sd.112) }\end{array}$ & $\begin{array}{l}198 * * * \\
\text { (sd. 108) }\end{array}$ & $\begin{array}{c}t(35)=3.76 \\
p=.001\end{array}$ \\
\hline EV (RCDI) & $\begin{array}{c}1.03 \\
\text { (sd.1.75) }\end{array}$ & $\begin{array}{c}2.23 \\
\text { (sd.3.63) }\end{array}$ & $\begin{array}{c}t(14.2)=-1.14 \\
p=.272\end{array}$ & $\begin{array}{c}\mathbf{8 . 0} \text { *** } \\
(\mathbf{s d . 5 . 9 7 )}\end{array}$ & $\begin{array}{l}\begin{array}{l}\text { 33.3*** } \\
\text { (sd.39.4) }\end{array} \\
\end{array}$ & $\begin{array}{c}t(34.8)=3.53 \\
p=.001\end{array}$ & $\begin{array}{l}223 * * * \\
\text { (sd.138) }\end{array}$ & $\begin{array}{c}\text { 36.4**** } \\
\text { (sd. 42.9) }\end{array}$ & $\begin{array}{c}t(31.8)=6.19, \\
p<.001\end{array}$ \\
\hline IJA (ESCS) & $\begin{array}{c}19.5 \\
(\mathrm{sd} .14 .3)\end{array}$ & $\begin{array}{c}20.5 \\
\text { (sd.12.6) }\end{array}$ & $\begin{array}{c}t(45)=-0.23 \\
p=.819\end{array}$ & $\begin{array}{c}17.0 \\
\text { (sd.11.4) }\end{array}$ & $\begin{array}{c}19.6 \\
\text { (sd.9.29) }\end{array}$ & $\begin{array}{c}t(32)=0.70 \\
p=.487\end{array}$ & N/A & N/A & \\
\hline RJA (ESCS) & $\begin{array}{c}47.4 \\
(\mathrm{sd} .23 .6) \\
\end{array}$ & $\begin{array}{c}48.5 \\
\text { (sd.26.8) }\end{array}$ & $\begin{array}{c}t(47)=-0.15 \\
p=.885\end{array}$ & $\begin{array}{c}67.2 \\
\text { (sd.26.8) }\end{array}$ & $\begin{array}{c}81.3 \\
\text { (sd.17.2) }\end{array}$ & $\begin{array}{c}t(36)=1.96, \\
p=.058\end{array}$ & N/A & N/A & \\
\hline IBR (ESCS) & $\begin{array}{c}9.79 * \\
\text { (sd.5.95) }\end{array}$ & $\begin{array}{c}13.64 * \\
\text { (sd.5.98) }\end{array}$ & $\begin{array}{c}t(45)=-2.02 \\
p=.049\end{array}$ & $\begin{array}{c}12.2 * * \\
\text { (sd.5.43) }\end{array}$ & $\begin{array}{c}18.5 * * \\
\text { (sd.6.36) }\end{array}$ & $\begin{array}{c}t(32)=2.74, \\
p=.010\end{array}$ & N/A & N/A & \\
\hline
\end{tabular}

TD-TP1 - typically developing children, time point 1; TD-TP2- typically developing children, time point 2; TD-TP3 - typically developing children, time point 3; DS-TP1children with Down syndrome, time point 1; DS-TP2- children with Down syndrome, time point 2; DS-TP3-children with Down syndrome, time point 3; NVMA - nonverbal mental ability- total raw score on the Mullen's Scale of Early Learning (MSEL); AC - auditory comprehension; EC- expressive communication; TLS-total language score; PLS-4 -Pre-school Language Scales-4; RV - receptive vocabulary; EV-expressive vocabulary; RCDI-Reading Communicative Development Inventory; IJA- initiating joint attention; RJA-responding to joint attention; IBR - initiating behavioural requests; ESCS-Early Social Communication Schedule

The significant differences are in bold.

${ }^{*} \mathrm{p} \leq 0.05 ; * * \mathrm{p} \leq 0.01 ; * * * \mathrm{p} \leq 0.001$ 


\subsection{Between-group comparisons: Speech segmentation}

Eleven TD infants and 3 infants with DS were excluded from analyses due to being unable to complete the speech segmentation tasks.

\subsubsection{Strong-Weak condition}

Figures 2 and 3 show the distribution of recognition indices in the Strong-Weak speech segmentation task for the TD infants and infants with DS respectively

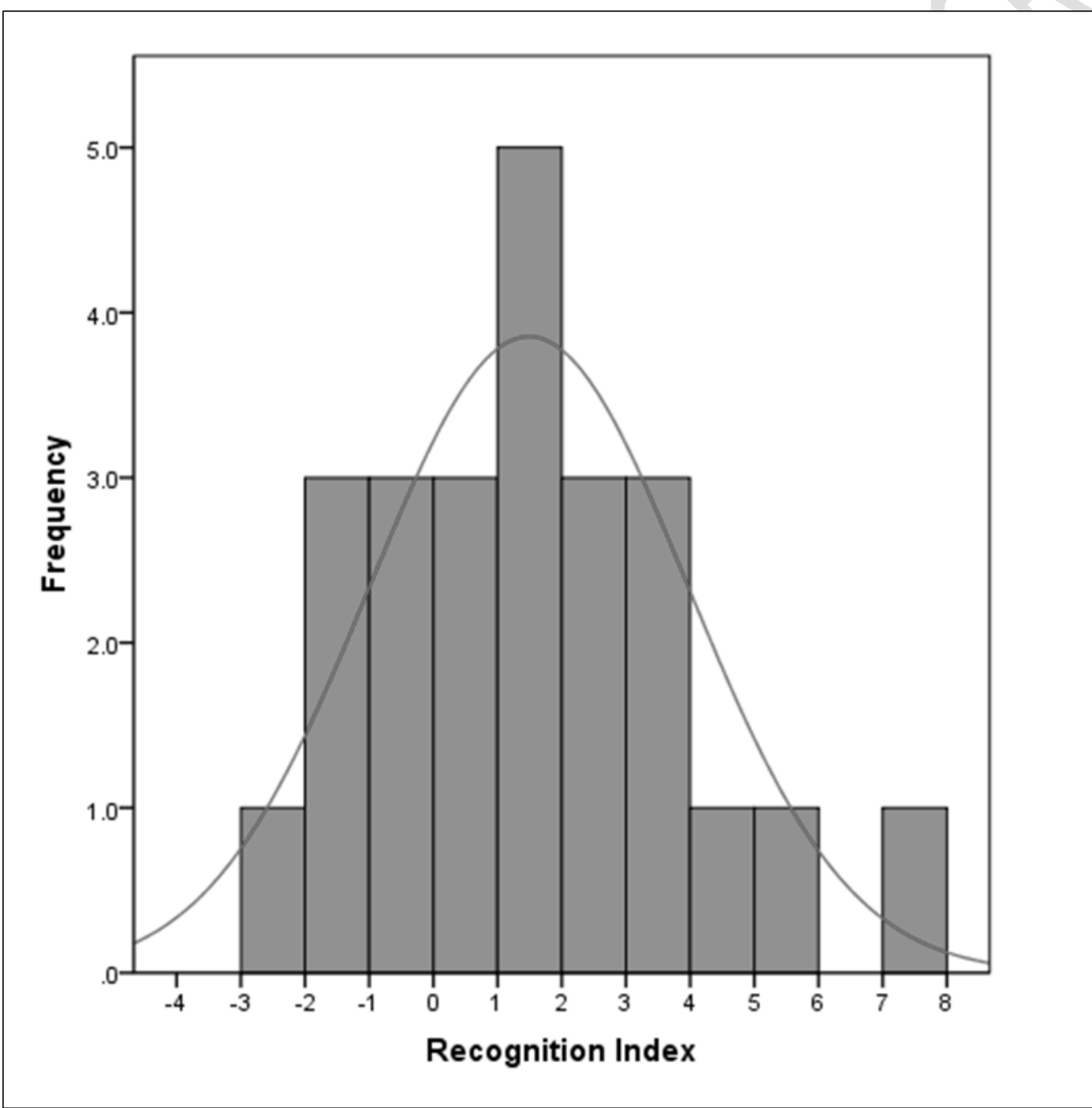

Figure 2: Distribution of recognition indices (in seconds) for the TD group in the Strong-Weak condition of the Speech Segmentation task 


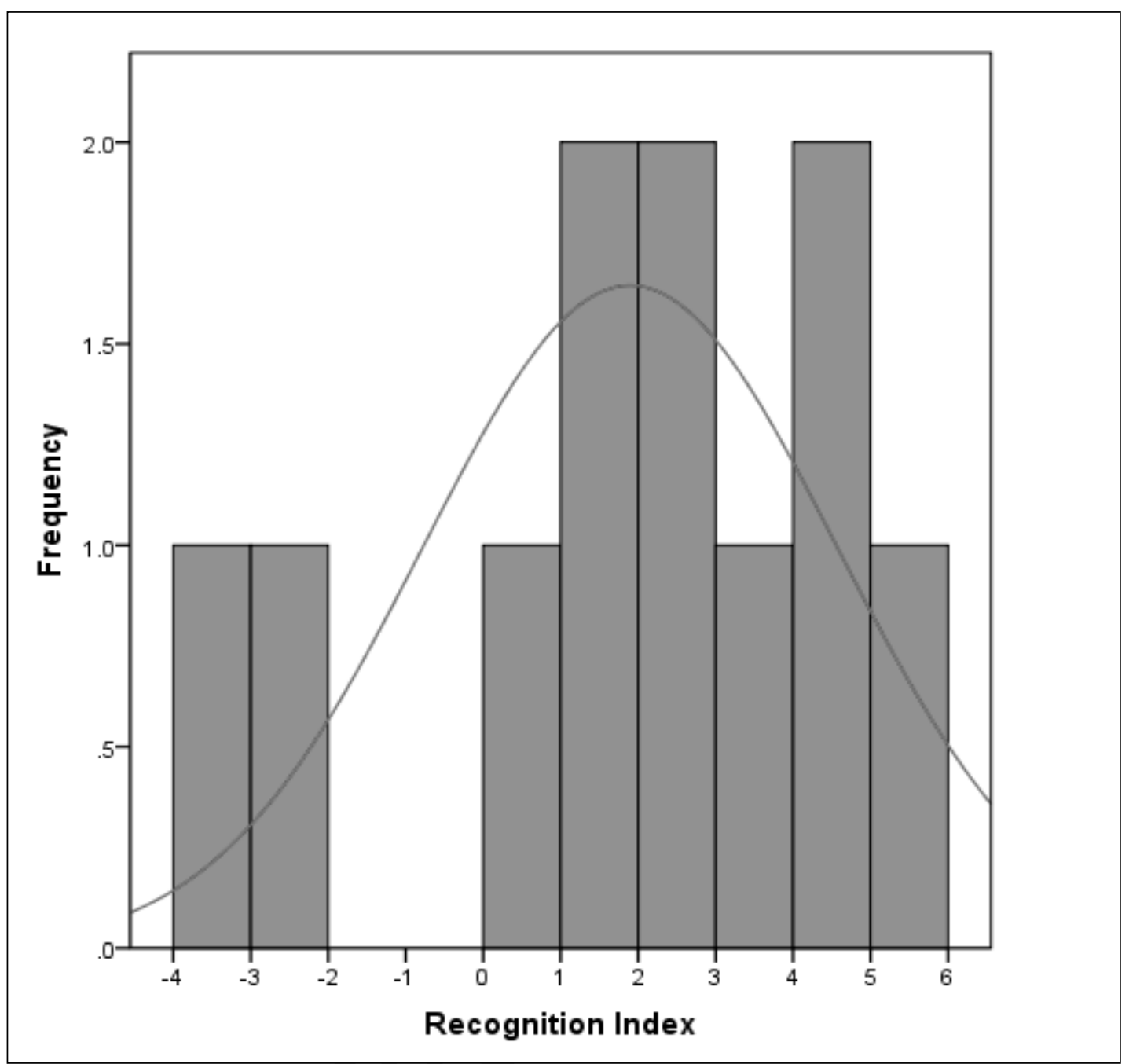

Figure Error! No text of specified style in document.. Distribution of recognition indices (in seconds) for the group of infants with DS in the Strong-Weak condition of the Speech Segmentation task

One-sample t-tests confirmed that the mean recognition indices for each group were significantly different from 0 for the TD group, $t(23)=2.94, p=.007$ (two-tailed), and the DS group, $t(10)=2.36, p=.040$ (two-tailed). This shows that both groups listened significantly longer to the passages containing words they had heard during the familiarisation phase, indicating that they could segment words with a strong-weak stress pattern from fluent speech. 
Figures 4 and 5 show the distribution of recognition indices in the Weak-Strong condition for the TD and DS groups respectively.

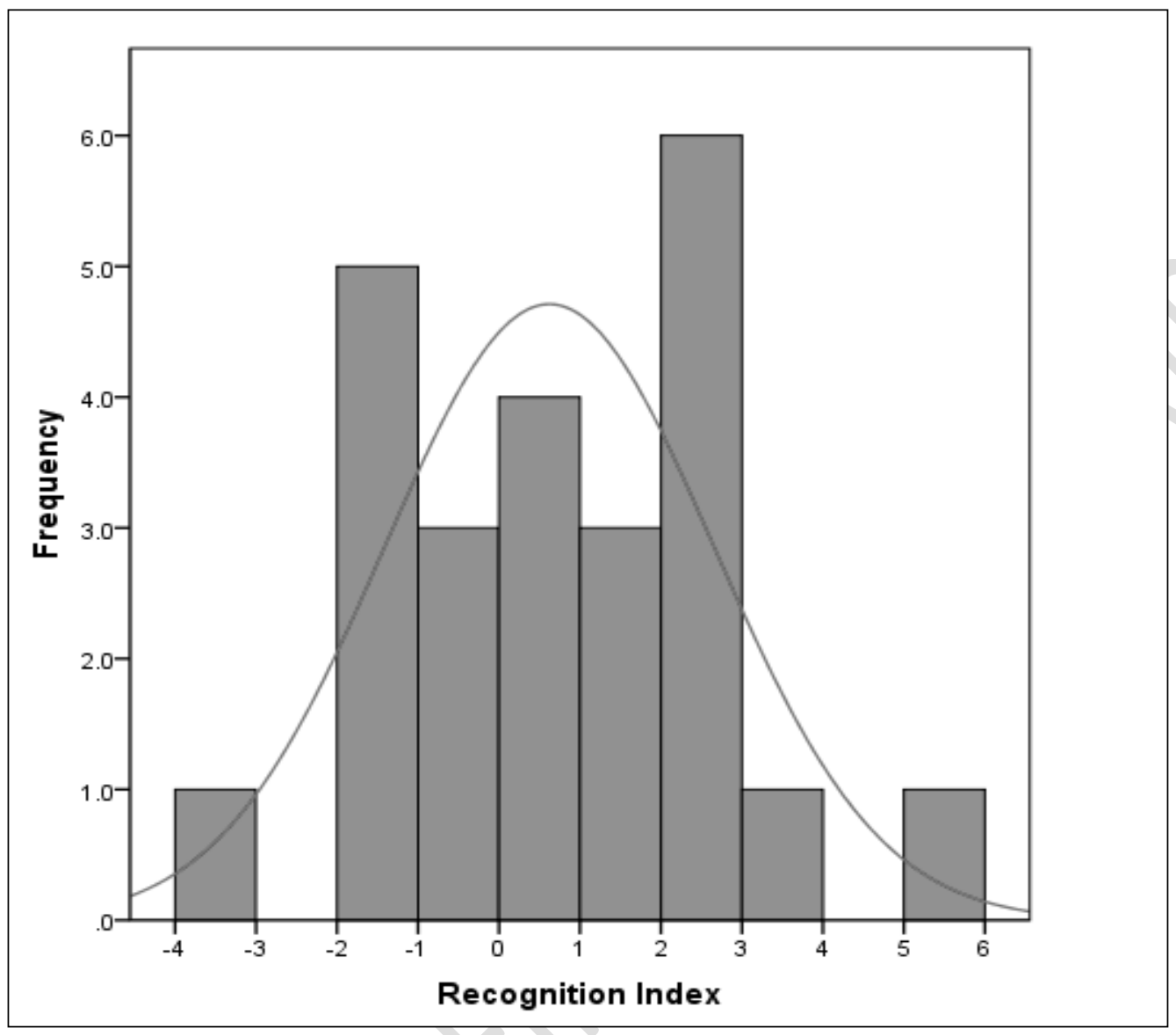

Figure 4: Distribution of recognition indices (in seconds) for the TD group in the WeakStrong condition of the Speech Segmentation task 


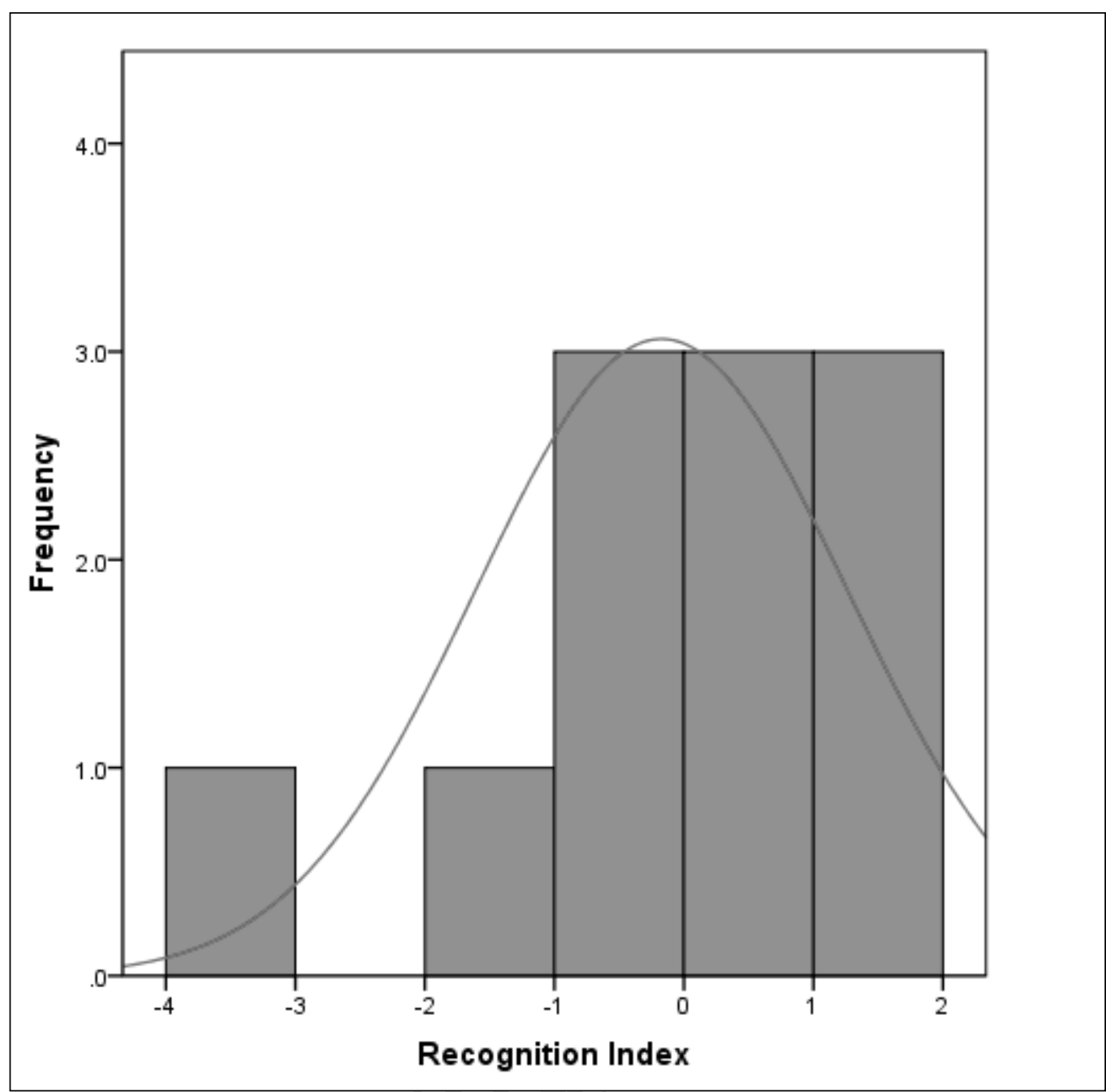

Figure 5: Distribution of recognition indices (in seconds) for the DS group in the WeakStrong condition of the Speech Segmentation task

One-sample t-tests confirmed that the mean recognition indices for neither group were significantly different from 0 (TD group: $t(23)=1.50, p=.148$; DS group: $t(11)=-.401, p=$ .697), indicating that neither group was able to segment words with a weak-strong stress pattern from fluent speech.

To investigate whether the two groups' performance was comparable on this task, a $2 \times 2$ mixed ANOVA was run, with condition as the within-subjects factor, and group as the between-subjects factor. There was a main effect of condition, $F(1,33)=5.56, p=.024$, no 
main effect of group $F(1,33)=.137, p=.714$, and no significant condition*group interaction $F(1,33)=.933, p=.341$, suggesting that there were no group differences on this task

\subsection{Longitudinal predictors of language}

All predictor measures (NVMA, speech segmentation score which was an average of recognition indices for both S-W and W-S conditions (SS), initiating joint attention, initiating behavioural requests, responding to joint attention) at Time Points 1 and 2, and language measures at Time Points 2 and 3 (EC, AC, Receptive Vocabulary and Expressive Vocabulary) were normally distributed. This was confirmed using a $-3 /+3$ criterion for Kurtosis and $-1 /+1$ for Skewness and Kolmogorov-Smirnov test of normality. One predictor variable which deviated from normality was initiating joint attention at TP1 for both groups and expressive vocabulary at TP2 for both groups.

Table 3 shows the partial correlations between predictor variables at TP1 and infants' language abilities 6 months later (at TP2) and 12 months later (TP3) for the TD group, controlling for Age. 
Table 3: Partial correlations between predictor variables at TP1 and language measures at TP2 and TP3 in Typically Developing infants (controlling for Age at TP1)

\begin{tabular}{|c|c|c|c|c|c|c|c|c|c|}
\hline \multicolumn{3}{|l|}{ Predictors } & \multicolumn{7}{|c|}{ Language measures } \\
\hline & & AC-TP2 & EC-TP2 & RV-TP2 & EV-TP2 & AC-TP3 & EC-TP3 & RV-TP3 & EV-TP3 \\
\hline \multirow[t]{3}{*}{ NVMA-TP1 } & $\mathbf{r}$ & -.087 & -.371 & -114 & -.320 & -.329 & -.323 & -.279 & -.359 \\
\hline & $\mathbf{p}$ & .667 & .057 & .542 & .079 & .076 & .082 & .187 & .084 \\
\hline & df & 25 & 25 & 29 & 29 & 28 & 28 & 22 & 22 \\
\hline \multirow[t]{3}{*}{ SS-TP1 } & $\mathbf{r}$ & .127 & $.701 *$ & .233 & $.553 *$ & $.498 *$ & $.685^{*}$ & $.565 *$ & .827 \\
\hline & $\mathbf{p}$ & .604 & .001 & .308 & .009 & .025 & .001 & .022 & $<.001$ \\
\hline & df & 17 & 17 & 19 & 19 & 18 & 18 & 14 & 14 \\
\hline \multirow[t]{3}{*}{ IJA-TP1 } & $\mathbf{r}$ & .381 & $.490 *$ & .237 & $.402 *$ & .206 & .230 & .292 & $.413 *$ \\
\hline & $\mathbf{p}$ & .055 & .011 & .215 & .030 & .769 & .240 & .177 & .050 \\
\hline & df & 24 & 24 & 27 & 27 & 26 & 26 & 21 & 21 \\
\hline \multirow[t]{3}{*}{ IBR-TP1 } & $\mathbf{r}$ & .337 & .285 & .088 & .171 & -.058 & -.104 & -.027 & .142 \\
\hline & $\mathbf{p}$ & .092 & .158 & .650 & .374 & .769 & .598 & .904 & .517 \\
\hline & df & 24 & 24 & 27 & 27 & 26 & 26 & 21 & 21 \\
\hline \multirow[t]{3}{*}{ RJA-TP1 } & $\mathbf{r}$ & -.319 & -.212 & .255 & -.039 & .146 & .126 & .296 & .110 \\
\hline & $\mathbf{p}$ & .105 & .287 & .166 & .834 & .441 & .508 & .160 & .609 \\
\hline & df & 25 & 25 & 29 & 29 & 28 & 28 & 22 & 22 \\
\hline
\end{tabular}

Key: $*$ = Significant Correlations; NVMA-TP1 = Non-Verbal Mental Ability at Time Point 1; IBR-TP1 = Initiating Behavioural Requests at Time Point 1; IJA-TP1 = Initiating Joint Attention at Time Point 1; RJA-TP1 = Responding to Joint Attention at Time Point 1;SS-TP1 = Speech Segmentation at Time Point 1. AC-TP2 = Auditory Comprehension at Time Point 2; EC-TP2 = Expressive Communication at Time Point 2; RV-TP2 = Receptive Vocabulary at Time Point 2EV-TP2 = Expressive Vocabulary at Time Point 2; AC-TP3 = Auditory Comprehension at Time Point 3; EC-TP3 = Expressive Communication at Time Point 3; RV-TP3 = Receptive Vocabulary at Time Point 


\subsubsection{TP1 predictors of language at TP2: TD group}

No measure was related to AC or Receptive Vocabulary (RV) scores at TP2. However, SS-TP1 and IJA-TP1 scores were correlated with EC-TP2 and Expressive Vocabulary- (EV-TP2) scores.

Regression analysis was used to assess how much variance in EC-TP2 scores was accounted for by SS-TP1 and IJA-TP1 scores, over and above Age and initial language ability. With Age and EC-TP1 entered as predictors in Block 1, the model was nonsignificant (Adj $\left.\mathrm{R}^{2}=.199, F(2,17)=3.35, p=.059\right)$. The addition of SS-TP1 in Block 2 significantly improved the model $\left(\mathrm{R}^{2}\right.$ change $=.404, F$ change $\left.(1,16)=20.41, p<.001\right)$. The addition of IJA1 also significantly improved the model $\left(\mathrm{R}^{2}\right.$ change $=.144, F$ change $(1,15)=$ 12.63, $p=.003)$, and the overall model was significant $\left(\operatorname{AdjR}^{2}=.783, F(4,15)=18.17\right.$, $\mathrm{p}<0.001)$.

To assess how much variance in EV-TP2 was accounted for by SS-TP1 and IJA-TP1 scores, a regression analysis was carried out with Age entered into Block 1, SS-TP1 entered into Block 2, and IJA-TP1 entered into Block 3. Since infants were performing at floor on EV-TP1, this variable was not controlled for in analyses. With just Age entered as a predictor, the model was non-significant (Adj $\mathrm{R}^{2}=.021, F(1,20)=1.45, p=.242$ ). The addition of SS-TP1 significantly improved the model $\left(\mathrm{R}^{2}\right.$ change $=.280, F$ change $(1,19)=$ $8.14, p=.010)$. The addition of IJA-TP1 also significantly improved the model $\left(\mathrm{R}^{2}\right.$ change $=$ $.139, F$ change $(1,18)=4.87, p=.041)$, and the overall model was significant $\left(\operatorname{Adj}^{2}=.401\right.$, $F(3,18)=5.68, \mathrm{p}=.006)$.

In the TD group, therefore, expressive language at TP2 was predicted by speech segmentation ability and initiation of joint attention six months earlier. 


\subsubsection{TP1 predictors of language at TP3: TD group}

Table 2 shows that SS-TP1 was correlated with AC-TP3, RV-TP3 and EC-TP3, while both SS-TP1 and IJA-TP1 were correlated with EV-TP3.

Regression analysis was used to assess how much variance in AC-TP3 scores was accounted for by SS-TP1 scores. With only Age entered as a predictor in Block 1, the model was non-significant $\left(\right.$ Adj $\left.\mathrm{R}^{2}=-.052, F(1,19)=.007, p=.934\right)$. Adding SS-TP1 in Block 2 significantly improved the model $\left(\mathrm{R}^{2}\right.$ change $=.241, F$ change $\left.(1,18)=5.73, p=.028\right)$, but the overall model remained non-significant, $\left.\operatorname{Adj}^{2}=.157, F(2,18)=2.87, \mathrm{p}=.083\right)$.

A similar analysis investigated how much variance in RV-TP3 scores was accounted for by SS-TP1 scores. Since RV-TP1 scores were not correlated with RV-TP3 scores, RVTP1 scores were not controlled for. With Age entered as a predictor in Block 1, the model was not significant (Adj $\mathrm{R}^{2}=.068, F(1,15)=1.10, p=.311$ ). Adding SS-TP1 in Block 2 significantly improved the model $\left(\mathrm{R}^{2}\right.$ change $=.259, F$ change $\left.(1,14)=5.39, p=.036\right)$ but the overall model remained non-significant, $\left(\operatorname{Adj}^{2}=.231, F(2,14)=3.40, \mathrm{p}=.062\right)$.

Regression was also used to explore how much variance in EC-TP3 scores was accounted for by SS-TP1 scores over and above Age and initial language. With Age and EC$\mathrm{TP} 1$ entered as predictors in Block 1, the model was non-significant (Adj $\mathrm{R}^{2}=.089, F(2,18)$ $=1.98, p=.167)$. Adding SS-TP1 significantly improved the model $\left(\mathrm{R}^{2}\right.$ change $=.374, F$ change $(1,17)=14.25, p=.002)$ and the overall model was significant $\left(\operatorname{Adj}^{2}=.475, F(3,17)\right.$ $=7.04, \mathrm{p}=.003)$.

Finally, a regression analysis assessed how much variance in EV-TP3 scores was accounted for by SS-TP1 and IJA-TP1 scores. Since infants performed at floor on EV-TP1, this variable was not controlled for. With Age entered as a predictor in Block 1, the model 
was non-significant (Adj $\left.\mathrm{R}^{2}=-.060, F(1,15)=.099, p=.757\right)$. Adding SS-TP1 in Block 2 significantly improved the model $\left(\mathrm{R}^{2}\right.$ change $=.634, F$ change $\left.(1,14)=24.74, p<.001\right)$. Adding IJA-TP1 in Block 3 did not significantly improve the model $\left(\mathrm{R}^{2}\right.$ change $=.026, F$ change $(1,13)=1.03, p=.329)$, but the overall model was significant $\left(\operatorname{Adj}^{2}=.591, F(3\right.$, $13)=8.70, \mathrm{p}=.002)$.

In sum, as at Time Point 2, early speech segmentation was a strong predictor of later expressive language of the TD group. However, social-communicative abilities did not play the same predictive role at TP3 as they had at TP2.

\subsubsection{TP1 Predictors of Language at TP2: DS group}

Pearson's correlations were run to assess the relationships between the predictor measures at TP1 and language scores at TP2 and TP3 when controlling for Age at TP1 (table 4). Following this, significantly correlated predictor measures were included in a regression model to investigate how much of the variance in each language variable was explained by these measures. 
Table 4: Partial correlations between predictor variables at TP1 and language measures at TP2 and TP3 in infants with Down Syndrome (controlling for Age at TP1)

\begin{tabular}{|c|c|c|c|c|c|c|c|c|c|}
\hline \multicolumn{3}{|l|}{ Predictors } & \multicolumn{7}{|c|}{ Language measures } \\
\hline & & AC-TP2 & EC-TP2 & RV-TP2 & EV-TP2 & AC-TP3 & EC-TP3 & RV-TP3 & EV-TP3 \\
\hline \multirow[t]{3}{*}{ NVMA-TP1 } & $\mathbf{r}$ & $.862 *$ & .383 & $.855 *$ & .553 & $.639 *$ & .469 & $.871 *$ & .528 \\
\hline & $\mathbf{p}$ & .001 & .245 & .003 & .097 & .025 & .124 & $<0.001$ & .095 \\
\hline & df & 9 & 9 & 7 & 8 & 10 & 10 & 9 & 9 \\
\hline \multirow[t]{3}{*}{ SS-TP1 } & $\mathbf{r}$ & -.206 & .468 & -.055 & .254 & -.317 & -.438 & -.226 & -.075 \\
\hline & $\mathbf{p}$ & .625 & .242 & .907 & .544 & .406 & .238 & .591 & .859 \\
\hline & df & 6 & 6 & 5 & 6 & 7 & 7 & 6 & 6 \\
\hline \multirow[t]{3}{*}{ IJA-TP1 } & $\mathbf{r}$ & .070 & .099 &.-486 & .012 & -.147 & .102 & -.185 & -.140 \\
\hline & $\mathbf{p}$ & .839 & .773 & .204 & .974 & .648 & .753 & .586 & .681 \\
\hline & df & 9 & 9 & 7 & 8 & 10 & 10 & 9 & 9 \\
\hline \multirow[t]{3}{*}{ IBR-TP1 } & $\mathbf{r}$ & .025 & -.538 & .141 & -.128 & .086 & .150 & .120 & -.242 \\
\hline & $\mathbf{p}$ & .942 & .087 & .718 & .725 & .790 & .641 & .725 & .474 \\
\hline & df & 9 & 9 & 7 & 8 & 10 & 10 & 9 & 9 \\
\hline \multirow[t]{3}{*}{ RJA-TP1 } & $\mathbf{r}$ & .469 & .080 & .384 & .466 & $.614 *$ & $.812 *$ & $.629 *$ & $.656^{*}$ \\
\hline & $\mathbf{p}$ & .145 & .816 & .307 & .174 & .034 & .001 & .038 & .028 \\
\hline & df & 9 & 9 & 7 & 8 & 10 & 10 & 9 & 9 \\
\hline
\end{tabular}

Key: $*$ = Significant Correlations; NVMA-TP1 = Non-Verbal Mental Ability at Time Point 1; IBR-TP1 = Initiating Behavioural Requests at Time Point 1; IJA-TP1 = Initiating Joint Attention at Time Point 1; RJA-TP1 = Responding to Joint Attention at Time Point 1;SS-TP1 = Speech Segmentation at Time Point 1.AC-TP2 = Auditory Comprehension at Time Point 2; EC-TP2 = Expressive Communication at Time Point 2; RV-TP2 = Receptive Vocabulary at Time Point 2;EV-TP2 = Expressive Vocabulary at Time Point 2; AC-TP3 = Auditory Comprehension at Time Point 3; EC-TP3 = Expressive Communication at Time Point 3; RV-TP3 = Receptive Vocabulary at Time Point 3; EV-TP3 = Expressive Vocabulary at Time Point 3 
As shown in Table 4, only NVMA-TP1 was significantly correlated with AC-TP2 and RV-TP2 when Age was controlled for. To assess how much variance in AC scores was accounted for by NVMA-TP1 over and above age and initial language status, a regression analysis was carried out with Age and AC-TP1scores entered into Block 1, and NVMA-TP1 entered into Block 2. With just Age and AC-TP1 entered as predictors, the model was significant (Adj $\mathrm{R}^{2}=.447, \mathrm{~F}(2,9)=5.45, \mathrm{p}=.028$ ). Adding NVMA-TP1 significantly improved the model $\left(\mathrm{R}^{2}\right.$ change $=.217, \mathrm{~F}$ change $\left.(1,8)=7.38, \mathrm{p}=.026\right)$, and the overall model was significant $\left(\operatorname{Adj}^{2}=.677, F(3,8)=8.67, \mathrm{p}<0.007\right)$.

To assess how much variance in RV scores was accounted for by NVMA-TP1 scores over and above Age and initial language status, a regression analysis was carried out with Age and RV-TP1 entered into Block 1, and NVMA-TP1 entered into Block 2. With just Age and RV-TP1 entered as predictors, the model was significant $\left(\mathrm{Adj} \mathrm{R}^{2}=.857, F(2,7)=28.05\right.$, $p<.001)$. Adding NVMA-TP1 did not improve the model $\left(\mathrm{R}^{2}\right.$ change $=.025, F$ change $(1,6)$ $=1.70, p=.240)$, although this remained significant $\left(\operatorname{Adj}^{2}=.870, F(3,6)=21.140, \mathrm{p}=0.001\right)$.

\subsubsection{TP1 predictors of language at TP3:DS group}

NVMA-TP1 and RJA-TP1 were both correlated with AC-TP3 and RV-TP3 scores, while RJA-TP1 was correlated with EC-TP3and EV-TP3.

Regression was used to assess how much variance in AC-TP3 scores was accounted for by NVMA-TP1 and RJA-TP1 scores. Since AC-TP1 scores were not correlated with ACTP3 scores, the former were not controlled for. With Age entered as a predictor in Block 1, the model was non-significant (Adj $\left.\mathrm{R}^{2}=-.091, F(1,11)=.000, p=.999\right)$. The addition of NVMA-TP1 significantly improved the model $\left(\mathrm{R}^{2}\right.$ change $=.408, F$ change $(1,10)=6.89, p=$ .025 ), but the overall model was non-significant (Adj $\mathrm{R}^{2}=.290, F(2,10)=3.45, p=.073$ ). Adding RJA-TP1 in Block 2 did not significantly improve the model $\left(\mathrm{R}^{2}\right.$ change $=.141, F$ 
change $(1,9)=2.82, p=.128)$, and the overall model remained non-significant $\left(\operatorname{Adj}^{2}=.399\right.$, $F(3,9)=3.652, \mathrm{p}=.057)$.

A further regression analysis investigated the contribution of NVMA-TP1 and RJATP1 scores to Receptive Vocabulary scores at TP3. When Age and RV-TP1 were entered as predictors in Block 1, the model was significant (Adj $\left.\mathrm{R}^{2}=.770, F(2,7)=19.45, p=.001\right)$. Adding NVMA-TP1 in Block 2 did not significantly improve the model $\left(\mathrm{R}^{2}\right.$ change $=.052, F$ change $(1,8)=3.07, p=.118)$, nor did the addition of RJA-TP1 in Block $3\left(\mathrm{R}^{2}\right.$ change $=.014$, $F$ change $(1,7)=.826, p=.394)$, but the overall model remained significant $\left(\operatorname{AdjR}^{2}=.809\right.$, $F(4,7)=12.662, p=.003)$.

The next analysis assessed how much variance in Expressive Communication scores at TP3 was accounted for by RJA-TP1 scores. Since EC-TP1 scores were not correlated with EC-TP3 scores, the former were not controlled for. With Age entered as a predictor in Block 1 , the model was non-significant $\left(\right.$ Adj $\left.\mathrm{R}^{2}=-.049, F(1,11)=1.62, p=.229\right)$. Adding RJA-TP1 significantly improved the model $\left(\mathrm{R}^{2}\right.$ change $=.576, F$ change $\left.(1,10)=19.47, p=.001\right)$, and the overall model was significant $\left(\operatorname{Adj}^{2}=.645, F(2,10)=11.906, p=.002\right)$.

The final analysis assessed the contribution of RJA-TP1 to variance in EV-TP3. Since EV-TP1 scores were not correlated with EV-TP3 scores, the former were not controlled for. With Age entered as a predictor in Block 1, the model was non-significant (Adj $\mathrm{R}^{2}=-.047$, $F(1,10)=.506, p=.493)$. Adding RJA-TP1 significantly improved the model $\left(\mathrm{R}^{2}\right.$ change $=$ $.423, F$ change $(1,9)=7.20, p=.025)$, but the overall model remained non-significant $\left(\right.$ Adj $^{2}$ $=.354, F(2,9)=4.012, \mathrm{p}=.057)$.

In the DS group, therefore, expressive language at TP3 is predicted by responsiveness to joint attention 12 months earlier. 


\subsection{Discussion}

This study provides the first longitudinal investigation of the development of language in TD infants and infants with DS in relation to infants' early non-verbal cognitive ability, speech segmentation and early social communication skills. To ensure the groups did not differ on NVMA at the start of the study, the infants with DS were almost twice as old (19 months) as the TD infants (10 months). Both groups were followed up 6 and 12 months later. The study found that the predictors of language outcomes were different for the two groups. Findings are discussed for each group in turn, followed by a consideration of the theoretical implications of the work.

For the TD group, the strongest predictors of language outcomes after 6 (TP2) and 12 (TP3) months were speech segmentation ability (SS) and initiating joint attention (IJA) at 10 months of age (TP1). After controlling for initial language status, SS at TP1 was a unique predictor of Expressive Communication and Expressive Vocabulary at TP2 and of Auditory Comprehension, Expressive Communication, Receptive and Expressive Vocabulary at TP3. IJA at TP1 also uniquely predicted Expressive Communication and Expressive Vocabulary at TP2, and was related to Expressive Vocabulary at TP3, but did not explain unique variance over and above SS. None of the measures taken at TP2 predicted language scores at TP3.

Little previous work has explored the prospective predictive value of speech segmentation ability in TD infants. In a retrospective study, Newman et al. (2006) found that infants who performed better on speech segmentation tasks between 7.5 and 12 months of age had larger vocabularies at age 2 and better language scores at age 4 . We built on their work by using a continuous measure of SS ability, rather than a simple pass/fail classification, and by controlling for infants' initial language status in analyses. Our findings corroborate those of a recent study by Singh, Reznick, and Xuehua (2012), who reported that 
speech segmentation ability at 7.5 months was strongly associated with productive vocabulary at 24 months. In addition, speech segmentation was a unique predictor of later language over and above earlier measures of language and joint attention. Speech segmentation skills are clearly very important for typical language acquisition.

Our finding of a relationship between the ability to initiate joint attention at 10 months and expressive language at 16 and 23 months also supports previous reports (Camaioni, et al.,1991; Mundy et al., 1988; Ulveand \& Smith, 1996). While the literature is inconclusive regarding whether IJA explains unique variance in later language when accounting for initial language (and other predictors), our work showed that IJA at 10 months of age explained unique variance in expressive language 6 months later, even when age, speech segmentation ability, and initial language status were controlled.

In contrast, for infants with DS, non-verbal mental ability (NVMA) and the ability to respond to joint attention (RJA) at 19 months of age were the strongest predictors of later language. NVMA at TP2 was related to Auditory Comprehension and Receptive Vocabulary scores 6 months later, but did not explain unique variance in scores once initial language was accounted for. RJA scores at TP1 uniquely predicted Expressive Communication and Expressive Vocabulary scores 13 months later, and were related to Auditory Comprehension and Receptive Vocabulary at TP3, although they did not explain unique variance in these over and above NVMA and initial language status. Scores for Initiating Behavioural Requests at TP2 were also related to Auditory Comprehension scores at TP3, but did not explain unique variance above NVMA.

The finding that RJA at 19 months of age in infants with DS explained unique variance in expressive language scores 13 months later contrasts with the results of Mundy, et al., (1995), Sigman and Ruskin (1999) and Zampini et al. (2015). Sigman and Ruskin (1999) 
reported that RJA was concurrently, but not longitudinally, related to language in their sample. This might be due to methodological differences. Sigman and Ruskin used only the Gaze-Following Task from the ESCS to measure RJA, while our measure combined the Gaze-Following and Book Presentation Tasks. The age of participants may also be a factor: the participants in Sigman and Ruskin's study were first tested at a mean age of 31 months (vs. 19 months in current study). Responding to joint attention typically emerges between 6 and 12 months of age, and is thought to facilitate language development by helping infants to avoid mapping errors during word learning. Sigman and Ruskin's participants may therefore have been 'too old' for this factor to be important longitudinally. Similarly, the ages of the participants in the Mundy et al., (1995) study ranged between 12 and 36 months; responding to joint attention may not be crucial for language acquisition at the upper end of this age range. Our findings also differ from those of Zampini et al. (2015), who reported that responding to joint attention was not predictive of later receptive vocabulary. The ages of the participants may again explain the differences in findings: our participants were on average 19 months of age, compared to 24 months in Zampini et al's study. There is evidence that the ability to respond to joint attention at 8, 10, 12 and 18 months (but not at 21 and 24 months) is related to later vocabulary development in TD children (Morales et al., 2000), and our results demonstrate that, at the early stages of language learning acquisition (i.e. before 24 months), RJA is very important for later language outcomes in infants with DS.

Studying the development of atypical populations such as individuals with DS, who present with an uneven pattern of development of language and non-verbal skills, allows us not only allows us to establish the precursors of language in this group, but also to address theoretical debates about language acquisition. If infants with DS develop language in a typical but delayed fashion, the same factors that predict language in TD children would be expected to predict language in children with DS, once they have reached a comparable stage 
of development in relation to the predictor skill. However, according to the neuroconstructivist approach (Karmiloff-Smith, 1998), genetic abnormalities affect developmental pathways, and the adult phenotype (characteristic language and cognitive profile) of individuals with disorders such as DS are the product of atypical developmental processes. According to this view, infants with DS develop language (and other cognitive skills) differently to TD infants, and different factors might predict language development in the two populations.

The results of the current study support the latter perspective. Although, at the start of the study, the infants with DS had similar NVMA to the TD infants and the two groups did not differ significantly on a range of factors important for language acquisition, different skills early in development predicted the language outcomes of the two groups. For example, NVMA was a significant longitudinal predictor of language for infants with DS but not for TD infants, suggesting that linguistic development in DS is more constrained by domaingeneral mechanisms. Furthermore, although both groups successfully segmented 'strongweak' words from fluent speech (at comparable non-verbal mental ages), speech segmentation only predicted language outcomes in the TD group. And while initiating joint attention was a crucial skill for TD infants, it was the ability to respond to joint attention that predicted language scores in DS participants. In combination, these findings suggest that speech segmentation ability may not crucial for language acquisition, or at least that language outcomes for infants with DS are more constrained by early social communication and cognitive skills. However, the drawing of definitive conclusions about group differences from the current study is hindered by the small sample of infants with DS, and the lack of correction for multiple tests of significance in our analyses. Given that "the effect sizes of correlates of language development are typically moderate" (Yoder \& Warren, 2004, p. 296), we considered that Bonferroni Correction would dramatically increase the risk of Type II 
Errors, and to a failure to discover predictors of language in our target population. A larger sample size is needed to confirm that speech segmentation skills are not related to language outcomes in infants with DS.

A further limitation of our study is that infants were only followed for one year. At the final time point, both groups were still in the early stages of language acquisition with limited vocabulary and little evidence of syntax. Since it is expressive language, and specifically syntax, that are particularly difficult for older children and adults with DS, further research to follow up the participants at a later time point is needed to establish whether early predictors of language in infants with DS remain relevant for language outcomes in the school years and beyond.

\section{References}

Adamson, L. B., Bakeman, R., Deckner, D. F., \& Romski, M. (2009). Joint Engagement and the Emergence of Language in Children with Autism and Down Syndrome. Journal of Autism and Developmental Disorders, 39(1), 84-96.

Bates, E., Thal, D., Whitesell, K., Fenson, L., \& Oakes, L. (1989). Integrating language and gesture in infancy. Developmental Psychology, 25, 1004-1019.

Blake, J. (2000). Routes to child language: Evolutionary and developmental precursors. Cambridge University Press.

Butterworth, G., \& Jarrett, N. (1991). What minds have in common is space: Spatial mechanisms serving joint visual attention in infancy. British journal of Developmental Psychology, 9, 55-72.

Camaioni, L., Castelli, M. C., Longobardi, E., \& Volterra, V. (1991). A parent report instrument for early language assessment. First Language, 11, 345-358. 
Caselli, M. C., Monaco, L., Trasciani, M., \& Vicari, S. (2008). Language in Italian children with Down syndrome and with specific language impairment. Neuropsychology, $22(1), 27-35$

Carpenter, M., Nagell, K., Tomasello, M., Butterworth, G., \& Moore, C. (1998). Social cognition, joint attention, and communicative competence from 9 to 15 months of age. Monographs of the Society for Research in Child Development, 63, i-174.

Chapman, R. S., Schwartz, S. E., \& Kay-Raining Bird, E. (1991). Language skills of children and adolescents with Down syndrome: I. Comprehension. Journal of Speech, Language, and Hearing Research, 34, 1106-1120.

Creagh-Osborne, R. \& Floccia., C. (2008), HeadTurn 1.7. School of Psychology, Plymouth University, UK.

Deák, G.O. (2014). Interrelations of language and cognitive development. Encyclopedia of Language Development (pp. 284-291). P. Brooks \& V. Kampe, Eds. SAGE

Delgado, C. E. F., Mundy, P., Crowson, M., Markus, J., Yale, M., \& Schwartz, H. (2002). Responding to joint attention and language development: A comparison of target locations. Journal of Speech, Language, and Hearing Research, 45, 715-719.

Desrochers, S., Morissette, P., \& Ricard, M. (1995). Two perspectives on pointing in infancy. In C.Moore \& P. J. Dunham (Eds.), Joint attention: Its origins and role in development (pp. 85-101). Hillsdale, NJ: Lawrence Erlbaum Associates, Inc.

Epstein, C. J. (1986). The consequences of chromosome imbalance. New York: Cambridge University Press.

Fodor, J.A. (1983). The modularity of mind. Cambridge, MA: MIT Press. 
Galeote, M., Sebastián, E., Checa, E., Rey, R., \& Soto, P. (2011). The development of vocabulary in Spanish children with Down syndrome: Comprehension, production, and gestures. Journal of Intellectual and Developmental Disability, 36(3), 184-196.

Hamilton, A., Plunkett, K., \& Schafer, G. (2000) Infant vocabulary development assessed with a British communicative development inventory. Journal of Child Language, 27 (3), 689-705

Harris, S., Kasari, C., \& Sigman, M. D. (1996). Joint attention and language gains in children with Down syndrome. American Journal of Mental Retardation, 100, 608-619.

Karmiloff-Smith, A. (1998). Development itself is the key to understanding developmental disorders. Trends in Cognitive Sciences, 2, 389-398.

Kasari, C., Freeman, S., Mundy, P., \& Sigman, M. D. (1995). Attention regulation by children with Down syndrome: Coordinated joint attention and social referencing looks. American Journal of Mental Retardation, 100(2), 128-136.

Martin, G. E., Klusek, J., Estigarribia, B., \& Roberts, J. E. (2009). Language characteristics of individuals with Down syndrome. Topics in Language Disorders, 29, 112-132.

McDuffie, A., Yoder, P., \& Stone, W. (2005). Prelinguistic predictors of vocabulary in young children with ASD. Hearing Research, 48, 1080-1097.

Mervis, C. B., \& Bertrand, J. (1997). Developmental relations between cognition and language: Evidence from Williams syndrome. In L. B. Adamson \& M. A. Romski (Eds.), Communication and language acquisition: Discoveries from atypical development (pp. 75-106). New York: Brookes.

Morales, M., Mundy, P., Delgado, C., Yale, M., Messinger, D., Neal, R., \& Scwartz, H. K. (2000). Responding to joint attention across the 6- through 24-month age period and 
early language acquisition. Journal of Applied Developmental Psychology, 21, 283298.

Mullen, E. M. (1995). Mullen scales of early learning (AGS ed.). San Antonio, TX: Pearson.

Mundy, P., \& Gomes, A. (1998). Individual differences in joint attention skill development in the second year. Infant Behaviour and Development, 21, 469-482.

Mundy, P., Hogan, A., \& Doehring, P. (1996). A Preliminary Manual for the Abridged Early Social Communication Scale (ESCS). Unpublished manuscript.

Mundy, P., Kasari, C., Sigman, M., \& Ruskin, E. (1995). Nonverbal communication and early language acquisition in children with Down syndrome and in normally developmental children. Journal of Speech, Language, and Hearing Research, 38, $157-168$.

Mundy, P., Sigman, M., Kasari, C., \& Yirmiya, N. (1988). Nonverbal communication skills in Down syndrome children. Child Development, 59, 235-249.

Næss, K. A. B., Lyster, S. A. H., Hulme, C., \& Melby-Lervåg, M. (2011). Language and verbal short-term memory skills in children with Down syndrome: A meta-analytic review. Research in Developmental Disabilities, 32, 2225-2234.

Nazzi, T., Paterson, S., \& Karmiloff-Smith, A. (2003). Early word segmentation by infants and toddlers with Williams syndrome. Infancy, 4, 251-271.

Newman, R., Ratner, N. B., Jusczyk, A. M., Jusczyk, P. W., \& Dow, K. A. (2006). Infants' early ability to segment the conversational speech signal predicts later language development: A retrospective analysis. Developmental Psychology, 42, 643-655.

Parker, S. E., Mai, C. T., Canfield, M. A., Rickard, R., Wang, Y., Meyer, R. E., et al. (2010). Updated national birth prevalence estimates for selected birth defects in the United 
States, 2004-2006. Birth Defects Research (Part A): Clinical and Molecular Teratology, 88, 1008-1016.

Pinker, S. (1999). Words and rules. London: Weidenfield \& Nicolson.

Sarant, J. Z., Hughes, K., \& Blamey, P. J. (2010). The effect on IQ on spoken language and speech perception development in children with impaired hearing. Cochlear Implants International, vol.11 (supplement 1), 370-374

Sigman, M., \& Ruskin, E. (1999). Continuity and change in social competence of children with autism, Down syndrome and developmental delays. Monographs of the Society for Research in Child Development, 64, 115-130.

Singh, L., Reznick, J. S., \& Xuehua, L. (2012). Infant word segmentation and childhood vocabulary development: a longitudinal analysis. Developmental Science, 15, 482495.

Smith, L., \& von Tetzchner, S. (1986). Communicative, sensorimotor, and language skills of young children with Down syndrome. American Journal of Mental Deficiency, 91, 57-66.

Stojanovik, V. (2014). Language in genetic syndromes and cognitive modularity. In

L.Cummins (Ed.), The Cambridge handbook of communication disorders. Cambridge, CUP. pp. 541-559

Ulveand, S., \& Smith, L. (1996). The predictive validity of nonverbal communication skills in infants with perinatal hazards. Infant Behaviour \& Development, 19, 441-449. 
Watt, N., Wetherby, A. M., \& Shumway, S. (2006). Prelinguistic predictors of language outcome at 3 years of age. Journal of Speech, Language, and Hearing Research, 49, 1224-1237.

Yoder, P. J., \& Munson, L. J. (1995). The social correlates of co-ordinated attention to adult and objects in mother-infant interaction. First Language, 15, 219-230.

Yoder, P. J., \& Warren, S. F. (1993). Can developmentally delayed children's language development be enhanced through prelinguistic intervention. Enhancing Children's Communication: Research Foundations for Intervention, 2, 35-61.

Yoder, P. J., \& Warren, S. F. (1998). Maternal responsivity predicts the prelinguistic communication intervention that facilitates generalized intentional communication. Journal of Speech, Language and Hearing Research, 41, 1207.

Yoder, P. J., \& Warren, S. F. (2004). Early predictors of language in children with and without Down syndrome. American Journal on Mental Retardation, 109, 285-300.

Zampini, L., \& D'Odorico, L. (2011). Gesture production and language development: A longitudinal study of children with Down syndrome. Gesture, 11(2), 174-193.

Zampini, L., Salvi, A., \& D'odorico, L. (2015). Joint attention behaviours and vocabulary development in children with Down syndrome. Journal of Intellectual Disability Research, 59(10), 891-901.

Zimmerman, I. L., Steiner, V. G., \& Pond, R. E. (2002). Preschool language scales (4 ${ }^{\text {th }}$ ed.). San Antonio, TX: The Psychological Corporation

Acknowledgements

The research study was funded by the ESRC and DownsEd International. We would also like to thank all the participants for their time and continuous support. 


\section{Appendix 1}

Test Passages for Strong-Weak Target Nouns

\section{Kingdom}

Your kingdom is in a faraway place. The prince sailed past that kingdom last summer. He saw a ghost in this old kingdom. The kingdom started to worry him. He went to another kingdom. Now the big kingdom makes him happy.

Hamlet

Your hamlet lies in a valley. Far away from here is an old hamlet. The kids from the hamlet often sing. Another hamlet is in the country. People from that hamlet like to farm. They live in a rather big hamlet.

Doctor

The doctor saw you the other day. He's much younger than the old doctor. I think your doctor is very nice. He showed another doctor your picture. That doctor thought you ate a lot. Maybe someday you'll be a big doctor.

Candle

The candle that you liked has melted. She bought another candle at the shop. You put away the old candle. He gave that candle to you later. She found a place for the new big candle. Your candle is pretty and smells nice.

Test Passages for Weak-Strong Target Nouns

\section{Guitar}

Your guitar was really too fancy. There is another guitar at the back. He gave the boy a big guitar. The guitar really needs to be tuned. The man put away his old guitar. He bought that guitar from the music shop.

Surprise

The surprise should be appreciated. I wonder if she got the old surprise. I think the big surprise is coming. You'll have another surprise tomorrow. Your surprise might not last too long. At least she didn't get that surprise.

Balloon

Your balloon is funny and new. She gave another balloon to her son. The lady is holding an old balloon. I think that balloon belongs to him. Your dad bought himself a big balloon. The balloon on the shelf is so nice.

Device

Your device can do more than that. I think we need another device. He likes the device that makes ice cream. That device only fixes broken things. The big device is used to sew clothes. No one will ever miss that old device. 


\section{Appendix 2: Procedure for Speech Segmentation task}

At the start of each trial, a red light on the centre panel started flashing, to attract infants' attention towards the front of the booth, between the two speakers. Once the child had orientated towards the red light, the red light stopped flashing and one of the green lights above a speaker on one of the side panels started flashing. When the experimenter judged that the child had made a turn of at least $30^{\circ}$ in the direction of the speaker, the auditory stimulus started. The auditory stimulus for each trial was played until completion, unless the child failed to maintain the $30^{\circ}$ headturn towards the stimulus for 2 consecutive seconds, in which case the experimenter released the relevant control button. The green light continued flashing and the auditory stimulus continued for a maximum of 2 seconds after the button was released. If the infant looked back towards the green light within the 2 seconds, the experimenter pressed the button again, and the trial continued without interruption. However, if the infant looked away for longer than 2 seconds, the trial ended, and the next trial began when the experimenter pressed the button again. The computer used the experimenter's button presses to determine the duration of the infant's looks towards the stimulus on each trial (henceforth "orientation time"). The time spent looking away was not included in the orientation time.

Each experimental task began with familiarisation to two target words (kingdom and hamlet, or doctor and candle in the Strong-Weak Task; guitar and surprise, or balloon and device in the Weak-Strong Task), counterbalanced within each group. For example, in the Weak-Strong Task, half the participants were familiarized with guitar and surprise, and half with balloon and device. Infants heard repetitions of the two words on alternating trials until they accumulated 20 seconds of orientation time to each word. The side of presentation, and 
the word list played, varied randomly from trial to trial. Trials were played until completion, unless the child failed to maintain the $30^{\circ}$ headturn for 2 consecutive seconds, in which case the trial stopped. Therefore the minimum number of trials needed to accumulate 20 seconds of listening time to both target words was 4 ( 2 trials for each word, each 16.5 seconds long).

The test phase began immediately after the familiarisation phase, and involved 8 trials, 2 presentations each of the 4 passages relevant to the task, with trials were split into 2 blocks of 4 passages, and order of presentation of passages randomised in each block. As in the familiarisation phase, trials were played until completion, unless the child failed to maintain a $30^{\circ}$ headturn for 2 consecutive seconds, in which case the trial stopped. 